\title{
New evidence supports the role of orthodontics in improving well-being
}

Research undertaken at the University of Sheffield School of Clinical Dentistry has found that orthodontic treatment before the age of 18 years improves oral health-related quality of life (OHRQoL), with the most improvement being in emotional and social well-being. ${ }^{1}$

The paper was co-authored by Professor Philip Benson, the British Orthodontic Society's (BOS') Director of Research, with colleagues Hanieh Javidi and Mario Vettore. It is based on a systematic review and meta-analysis of studies using patient reported outcomes before and after orthodontic treatment.

The findings are highly significant for the orthodontic specialty because until now, there has been little evidence that orthodontic treatment improves OHRQoL. The paper has been welcomed by Professor Kevin O'Brien in his blog, ${ }^{2}$ one of the most widely read orthodontic information resources in the world.

Professor O'Brien said the research represented a 'large step' forward: 'As practising orthodontists we are constantly being told by our patients that they are pleased they had their teeth straightened and that they are no longer embarrassed to smile or to be photographed. We wanted to find all the research that has tried to measure this effect with young people.
'We did a thorough search and found 13 studies that were relevant. Four of these studies used similar questionnaires to measure what young people thought about their teeth and how their dental appearance affects their life, before and after orthodontic treatment. We combined the data from these four studies to show that the improvement was measurable and moderately large in the areas of emotional and social well-being.'

Professor Benson added that the overall number of young people included in the research was relatively small, so further research is needed.

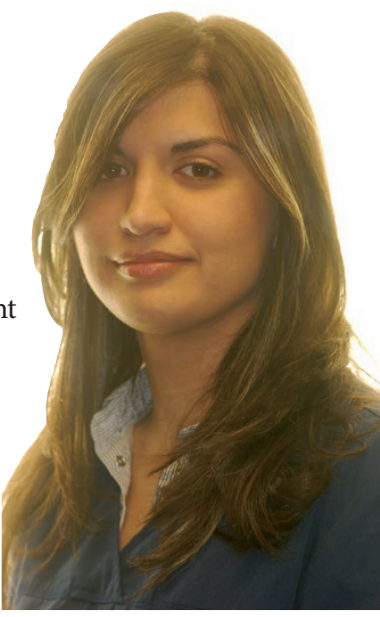

Hanieh Javidi Hanieh Javidi has just been awarded the 2017 joint Faculty of Dental Surgery Royal College of Surgeons (Eng) - British Orthodontic Society Research Fellowship and her PhD research project will investigate OHRQoL in the under 18 age group further.

1. Javidi $H$, Vettore M, Benson P E. Does orthodontic treatment before the age of 18 years improve oral health-related quality of life? A systematic review and meta-analysis. Am $J$ Orthod Dentofacial Orthop 2017; 151: 644-655.

2. O'Brien K. Orthodontic treatment improves quality of life! 10 April 2017. Available at: http:// kevinobrienorthoblog.com/orthodontic-treatment-improves-quality-life/ (accessed May 2017). 